\title{
Wind Turbine Blade Aerodynamic Design and Optimization
}

\author{
Cláudio Tavares da Silva \\ Ana Paula Carvalho da Silva Ferreira \\ Augusto Bemben Costa \\ Lucas Gonçalves Araujo \\ Universidade Tecnológica Federal do Paraná, UTPFR \\ Departamento Acadêmico de Mecânica, DAMEC-CT \\ Curitiba
}

\begin{abstract}
Traditionally, the aerodynamic design of a wind turbine blade depends on the choice of one or more airfoils to be used along its span. The experience and ability of the designer is necessary at this phase of the design processes. The method developed in this paper intends to mitigate this need. A genetic algorithm is specially designed to determinate the aerodynamic design parameters of the blades and the selection of the airfoils. This first approach uses thin airfoil theory. The Blade Element Momentum Method is used as fitness function for the evaluation of each individual's power coefficient within the domain considered by the genetic algorithm. The study case of this paper achieved good results, reaching power coefficients greater than 55\%, figure close to the theoretical limit of 59\% defined by the conservation of linear momentum theory.
\end{abstract}

Keywords: Wind turbine blade, optimization design, genetic algorithm, stationary blade element method, airfoil selection.

\section{Introduction}

The search for clean, reliable and qualified energy sources is one of the great needs of the modern world, as pointed out by the UN (2015). An alternative way out is to permit the consumer to achieve some energy independence and be less exposed to the variations of the energy market. In this context, micro energy generation is a very interesting solution, especially considering the wind and solar energies conjoined generation. The micro-generation is defined as the installed power limit of $100 \mathrm{~kW}$ or less that uses renewable sources such as hydropower, solar, wind, biomass or qualified cogeneration and connected to the distribution network. The mini-generation has power limit at 1 MW, according URSAIA (2015).

The objective of this work is the development of a computational tool capable of providing the optimum aerodynamic design parameters of a horizontal axis micro or mini wind turbine blade based only on the average wind speed and the power output. The design is developed using thin airfoils and their numerical fluid dynamics simulation data. They are used at this point with the intention to achieve a simpler and cheaper manufacturing process for the final product. The aerodynamic parameters of the blades are optimized to extract the maximum possible power from the flow. The aerodynamic parameters optimized are: rotor diameter, chord and geometric torsion distribution of the blades and curvature of blade element. Defined by an initial basic design, the blades are optimized using Genetic Algorithm, maximizing the extracted power at each iteration, calculated by the Blade Element Momentum Method (BEM) BURTON (2001).

\section{Theoretical Foundation}

\subsection{Blade Element Momentum Method (BEM)}

It is a method to understand the flow through the rotor of the wind turbine, which divides the flow tube passing through into parts, the so-called blade elements, by discretizing it into a number of ring-shaped elements, as shown in Figure 1 (author ref.). The following hypotheses are assumed in this method: there is no radial dependence, that is, one blade element has no influence on another; the force exerted by the blades upon the flow is constant on each annular element, i.e., the rotor is supposed to be composed of an infinite number of blades. 


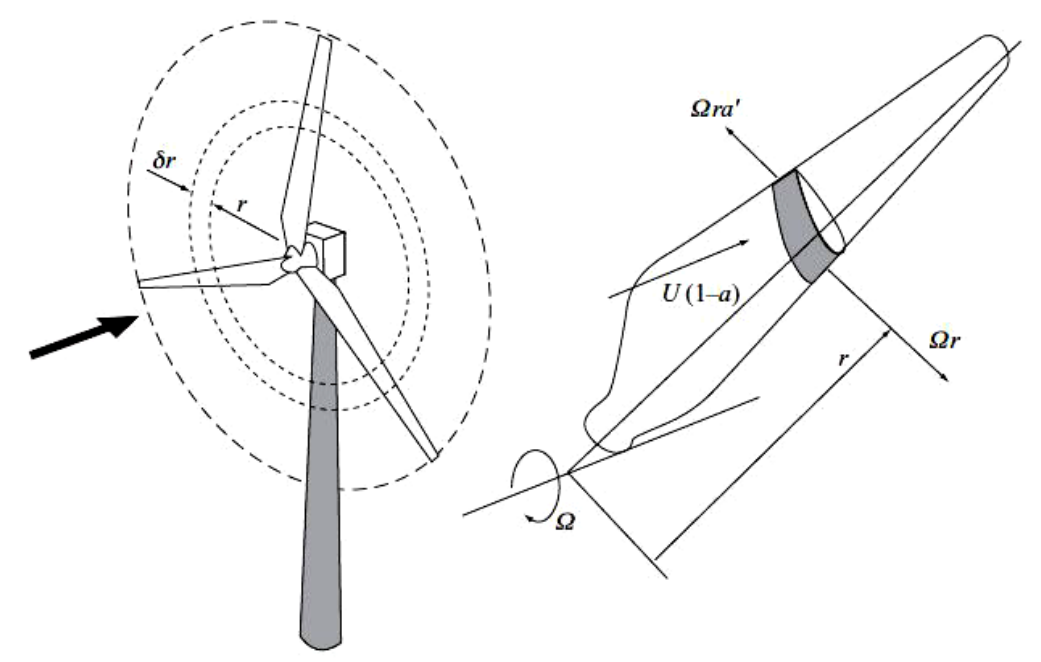

Figure 1 - Annular blade element (BURTON, 2001)

The method enables to calculate the steady loads and also the thrust and power using different settings on wind speed, rotational speed and pitch angle. In each blade element, the induced velocity is calculated by performing the conservation of momentum analysis, and the aerodynamic forces are found from the 2D aerodynamic theory and airfoil data. The lateral boundary of the elements does not admit any flow across them according the hypothesis of no radial dependency. Besides that, the flow over the rotor blades airfoils is considered to be stationary. In order to take into account a rotor with a finite number of blade, a correction known as Prandtl's tip loss factor (Glauert, 1935) is introduced to correct this latter assumption.

Relative velocity $V_{r e l}$ observed by the blade section is a combination of $V_{0}(1-a)$ and $r \omega\left(1+a^{\prime}\right)$. The axial and tangential induction factor at the rotor plane (Figure 2) are denoted by $a$ and $a^{\prime}$ respectively. $\theta$ is the local pitch angle. They need to be obtained by recursive calculation.

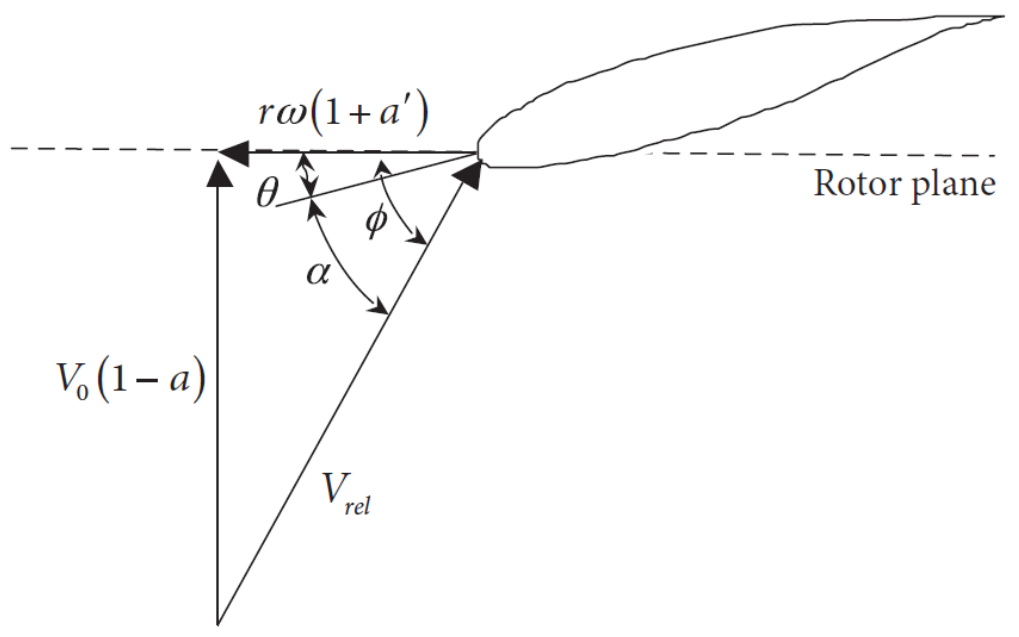

Figure 2. Velocities at rotor plane.

Since different control volumes are assumed independent, the following algorithm is applied for each control volume. The summarized algorithm for the BEM method follows the sequence of steps.

Step (1): Initialize axial and radial induction factors, typically $a=a^{\prime}=0$.

Step (2): Compute the flow angle $\phi$.

Step (3): Compute the local angle of attack $\alpha$.

Step (4): Read the lift $C_{l}(\alpha)$ and drag $C_{d}(\alpha)$ coefficients from a table.

Step (5): Compute $C_{n}$ and $C_{t}$, respectively normal and tangential aerodynamic force coefficients.

Step (6): Recalculate $a$ and $a^{\prime}$. 
Step (7): If the induction factors have changed more than a tolerable amount, repeat step (2), or else finish. Step (8): Compute local loads on the blade element.

Burton (2001) and Hansen, Martin (2007), describe in detail, all equations necessary to perform the above algorithm.

\subsection{Blade Optimization}

Thin airfoils are used to design the blade, looking forward to the manufacturing process using composite materials. The thin airfoils are supposed to be composed of two segments of circumference of the same length joined by a third segment of circumference of radius equal to $0.5 \%$ of the chord. It is defined in this way in order to obtain a maximum thickness of $1 \%$ to meet the thin profile criteria required for numerical simulation. The camber is defined by the ratio of the total length of the chord and the radius of the definition circle of the camber line. An example of such airfoil, of curvature 0.75, is shown in Figure 3.

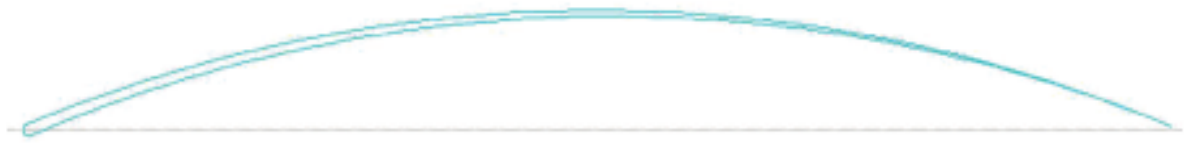

Figure 3 - Airfoil 0,75

An $C_{1}$ and $C_{d}$ data bankis mounted simulating a series of 150 airfoils with curvatures from 0,01 to 1,50 and varying the Reynolds number from $10^{3}$ to $10^{6}$ and angles of attack from 0 to 20 degrees.

\subsection{Optimization Problem}

A genetic algorithm with 25 generations of a population of 25 individuals. The design parameter optimizedare: rotor diameter $(\mathrm{R})$, airfoil camber $(\mathrm{g})$ and chord length $(\mathrm{c})$. The fitness function is the power coefficient $\left(\mathrm{C}_{\mathrm{P}}\right)$.

The following restrictions are also used: power extracted must be equal of greater than the nominal one, the axial induction factor must be between 0 and $1 / 3(0<\mathrm{a}<1 / 3)$ and the tangential induction factor must be positive $\left(\mathrm{a}^{\prime}>0\right)$.

\subsection{Fitness function}

In genetic algorithms the fitness function value is the evaluation parameter of the candidates of a population of solutions. In this work, the fitness function is directly obtained using the power extracted on the rotor blades. This way, the code steps are in themselves the steps of aerodynamic design of wind turbine blades using the Blade Element Momentum Method (BEM).The objective of the BEM is to define axial (a) and tangential (a') induction factors so that one can evaluate the influence of a blade element in the flow and the result of that influence on the blade element itself. By defining the induction factors for all blade elements along the span, one can determine the aerodynamic forces acting over an element, and consequently, the torque and power extracted by the blade and the rotor.

From a minimum allowable, the rotor diameter is gradually increased until it is able to extract the required power. For each diameter tested, the tip speed ratio $(\lambda)$ is evaluated from 1 to 15 , in increments of 0.1 , producing a power curve with maximum value at some point in that domain. When it reaches the maximum value of power, the code verifies if the power founded is at least equal to the required one and, if this condition is satisfied, the fitness function code is finished. If the condition is not satisfied, the diameter is incremented by a width of 1 (one) blade element and the span is again subdivided. So that the number of blade elements is constant, repeating the steps of the calculation of the induction factors and tip speed ratio $\lambda$.

For the calculation of the induction factors, it is necessary to use the values of the lift $\left(\mathrm{C}_{1}\right)$ and drag $\left(\mathrm{C}_{\mathrm{d}}\right)$ coefficients and the angle of attack $(\alpha)$ for each element. These coefficients and angle of attack are retrieved from the numerical simulation database created. For each airfoil the fitness function code finds the maximum value of the $\mathrm{C}_{1} / \mathrm{C}_{\mathrm{d}}$ ratio and the corresponding coefficients and angle $\alpha$ in order to provide the highest lift with the least drag for each blade element. When $\lambda>3$ the axial induction factor (a) should be corrected using the Prandtl loss factor. Thus, the correction is not applied throughout all the range of the values of $\lambda$ considered, which causes a discontinuity in the power curve at the point from which the Prandtl loss factor is included. If the maximum power value found corresponds to a $\lambda>3$ the correction is applied and the value of the power coefficient is then recalculated. Otherwise, the correction is not considered.

\section{Problem approach}

Airfoils with different curvatures are used in different points along the blade span. In this way, there are different groups of contiguous blade elements with the same curvature known by sectors. Each sector consists of an invariable amount of blade elements and all sectors along the blade have the same amount of blade elements. When working with sectors of elements of the same curvature one can approach the use of the genetic algorithm in two ways. 
On the first way, the candidates are blades with sectors where the curvature is manipulated through the crossover and mutation operations in the same way, over the entire blade span. In this approach, the same operation is performed in all sectors for each iteration. This optimization approach is referred to as "by blade" approach.

On the second way, the candidates are different aerodynamic curvature profiles where the goal is to work in each sector separately, independently, one after another. In this approach the crossover and mutation operations are performed for each sector's curvature, from the root to te tip, along the length of the blade. This optimization approach is referred as "by airfoil" approach.

The two approaches are used in this work allowing a comparison of the results and characterization of parameters for each of them. Both approaches make use of the BEM as fitness function and depart from the smallest possible diameter value calculated from the maximum efficiency value defined by the theoretical Betz limit. The chords lengths are calculated by Schmitz's theory, presented in Gasch and Twele (2002). The number of blade elements for both approaches is defined as 1000 .

\section{4 results}

These initial results are obtained with air speed of $3.5 \mathrm{~m} / \mathrm{s}$ and desired extracted power of $350 \mathrm{~W}$. The air speed used is half of the wind speed commonly considered commercially viable for wind energy extraction. This condition intends to simulate the mean speed found at urban conditions.

The adjustable parameters of the genetic algorithm are defined as: crossover probability is $50 \%$ and mutation probability is 5\%. These values are obtained using a decision matrix method, evaluating crossover probabilities of $25 \%$, $50 \%$ and $75 \%$ and mutation probabilities of 5\%,10\% and 15\% (ELMANSY, 2015).

\subsection{Results "by blade"}

The following results are obtained when the first optimization method is used. All elements of the entire blade are submitted to the optimization process.

Table 1. Simulation "by blade"

\begin{tabular}{ll}
\hline Results "by blade" & \\
\hline $\begin{array}{l}\text { Minimum rotor diameter } \\
\text { (Betz limit) }\end{array}$ & $5.496 \mathrm{~m}$ \\
Resulting rotor diameter & $5.594 \mathrm{~m}$ \\
Rotor speed & $69.307 \mathrm{rpm}$ \\
Tip speed ratio & 5.8 \\
Power coefficient & 0.57 \\
Computing time & 5.7 hours \\
\hline
\end{tabular}

Figure 4 shows the chord lengths distribution for the first method called "by blade".

The parameters resulted from this simulation are showed in table 1.

Figure 4 - Chord length optimization "by blade".

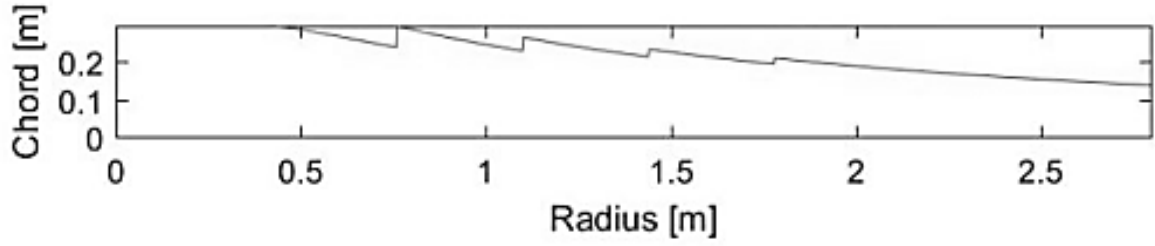

\subsection{Results "by airfoil"}

Figure 5 shows the chord lengths distribution for the second method called "by airfoils". 
Table 2. Simulation "by airfoil"

\begin{tabular}{ll}
\hline Results "by airfoil" & \\
\hline $\begin{array}{l}\text { Minimum rotor diameter } \\
\text { (Betz limit) }\end{array}$ & $5.496 \mathrm{~m}$ \\
Resulting rotor diameter & $5.587 \mathrm{~m}$ \\
Rotor speed & $71.786 \mathrm{rpm}$ \\
Tip speed ratio & 6.0 \\
Power coefficient & 0.57 \\
Computing time & 20.1 hours \\
\hline
\end{tabular}

The parameters resulted from this simulation are showed in table 2 .

Figure 5 - Chord length optimization "by airfoil".

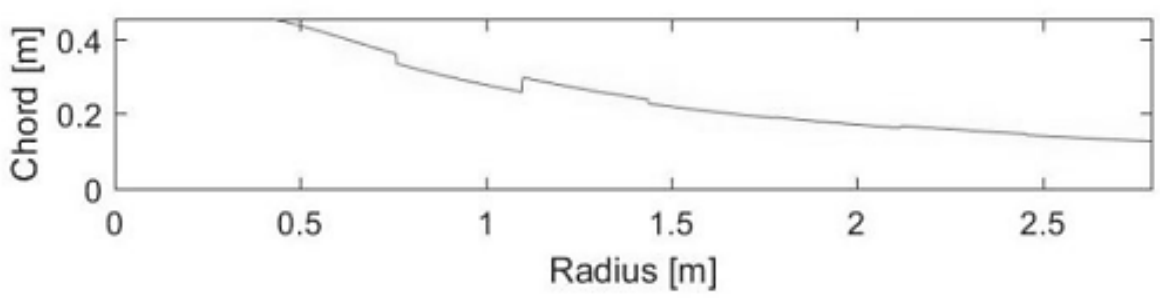

It is observed that the blade design generated with the "by airfoil" optimization and the one generated "by blade" optimization, presents similar parameters, except for the computational time, that is significantly greater in the "by airfoil" optimization. It is important to notice that the computing times obtained using both methods serve as comparison because the same computer is used. The "by airfoil" method is no longer used and only the results of the "by blade" method are refined.

Table 3. Curvatures distribution

\begin{tabular}{ll}
\hline Element coordinates $(\mathrm{m})$ & Camber \\
\hline $0.421-0.762$ & 1.44 \\
$0.764-1.104$ & 1.09 \\
$1.106-1.446$ & 1.05 \\
$1.448-1.788$ & 0.79 \\
$1.790-2.129$ & 0.66 \\
$2.132-2.471$ & 0.63 \\
$2.474-2.797$ & 0.41 \\
\hline
\end{tabular}

This blade generated with the "by blade" optimization has the airfoil cambers distribution shown in Table 3 . It is considered ahub with a radius of $0.420 \mathrm{~m}$.

The surface representing the resulting blade is generated and shown in Figure 6 - Blade surface. 
It is obviously noted that the interfaces between the sectors show significant discontinuities. For the blade construction it is necessary to smooth the chord and camber distribution. As the BEM method does not consider radial flow in the blade, these discontinuities do not influence its performance from a computational point of view. After the smoothing process, the power extracted and $\mathrm{C}_{\mathrm{P}}$ need to be recalculated.

\subsection{Results validation}

For comparison criteria, WENZEL (2007) is used as reference results. In that one, a wind turbine designed adopting the wind speed of $10 \mathrm{~m} / \mathrm{s}$ and aiming a power extraction of $350 \mathrm{~W}$. These are the input parameters. Using the method developed and the same inputs parameter stablished in WENZEL (2007), the chords distribution shown in Figure 7 is obtained.

Figure 7 - Chords distribution (10m/s wind speed)

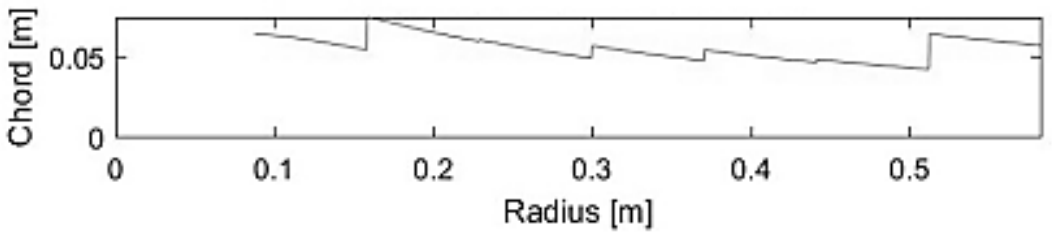

The parameters resulted from this simulation are showed in table 4.

Table 4. Simulation results for validation

\begin{tabular}{ll}
\hline Results "by airfoil" & \\
\hline $\begin{array}{l}\text { Minimum rotor diameter } \\
\text { (Betz limit) }\end{array}$ & $1.138 \mathrm{~m}$ \\
Resulting rotor diameter & $1.164 \mathrm{~m}$ \\
Rotor speed & $853.202 \mathrm{rpm}$ \\
Tip speed ratio & 5.2 \\
Power coefficient & 0.57 \\
Computing time & 7.9 hours \\
\hline
\end{tabular}

Table 5. Simulation results for validation

\begin{tabular}{llll}
\hline Results comparison & Diameter $(\mathrm{m})$ & $\mathrm{C}_{\mathrm{P}}$ & Rotor speed (rpm) \\
\hline This work & 1.164 & 0.57 & 853,202 \\
WENZEL (2007) & 1.504 & 0.40 & 634,520 \\
\hline
\end{tabular}

Table 5 shows a comparison of the available rotors resulting from this work and WENZEL (2007).

Through this comparison, one can observe the good quality of the result obtained in this work. The results shows that the method is capable of, based only in the wind conditions and power extraction, providing an optimized blade design with an automated airfoils selection process. It is also necessary to take into account that the aerodynamic airfoils used in this work are thin whereas in the work of WENZEL (2007), the profiles used are thick. But it is necessary to smooth the aerodynamic geometry of the blade in order to obtain more realistic results. This smoothing procedure results are shown in figure 8 .

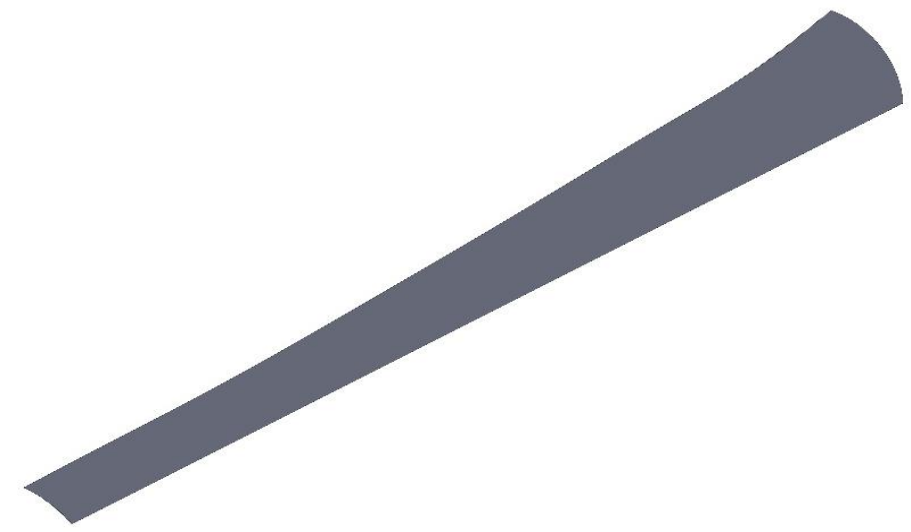

Figure 8 - Chordsdistribution (smoothed) $(10 \mathrm{~m} / \mathrm{s}$ wind speed) 
Table 6 shows a comparison of the available rotors resulting from this work after the smoothing procedure and WENZEL (2007).

Table 6. Simulation results for validation

\begin{tabular}{llll}
\hline Results comparison & Diameter $(\mathrm{m})$ & $\mathrm{C}_{\mathrm{P}}$ & Rotor speed (rpm) \\
\hline This work (smoothed) & 1.178 & 0.55 & 1005,18 \\
WENZEL (2007) & 1.504 & 0.40 & 634,52 \\
\hline
\end{tabular}

The results still have good quality. The increase in rotor speed is not a concern, once the rotor obtained has a reduced diameter. Furthermore, with thin airfoils, it is expected that the inertial forces involved are not too high due to the lower mass of the actual blade design obtained.

\section{Conclusions}

The present work shows itself as an excellent tool for wind turbine blade design, eliminating the need of blade airfoils pre selection. The results obtained show that the product of this work is coherent and able to produce designs for small wind generators of great efficiency, using thin airfoils. In comparison with the results of the work used as reference and validation, a better power coefficient with a smaller rotor diameter is obtained, considering the same wind conditions. This good quality in the results can be observed in the value for the power coefficient of 55\%, very close to the Betz limit of 59\%. This shows a good aerodynamic design for the rotor with optimum flow energy extraction. It is obvious that, after the smoothing process of the chords and airfoil cambers distribution, it is expected that the power coefficient will be reduced. But the value obtained here is very promising, showing the high potential of the developed process. It is believed that the computational algorithm developed in this work can be used in actual real design cases. The computational time to obtain the optimum design parameters, from the selected requirements, is below 6 hours, even with the algorithm running on a computer of common specifications.

A great contribution of this work lies in the achievement of its more ambitious objective. It is proposed to obtain a computational code capable of determining the optimum aerodynamic parameters for a mini wind generator design using thin airfoils and it is also capable of selecting the airfoils cambers along the blade span. Usually the airfoils are pre-selected, and they are treated as initial parameters. Moreover, the air foil selection depends fundamentally on the experience of the design engineer. From the obtained results, it is possible to affirm that the proposed objective is achieved. The code developed in this work is able to select the cambers along the span, which provide the highest possible efficiency in the extraction of wind energy. Taking into account that the camber of thin airfoils is aerodynamic equivalent to the curvature of the mean aerodynamic chord of the thick airfoils, the present work can also fil out as a starting point for large-scale wind turbine blades designs.

\section{References}

BURTON, T. at alli; "Wind Energy Handbook”, 2nd. Ed, Chichester, John Wiley \& Sons, 2001.

ELMANSY, R. "Decision matrix: How to make the right decision", 2015. Disposable at <http://www.designorate.com/decision-matrix-decision-making/>. Access in 12/05/2017.

Gash, R. and Twele, J., 2002, "Wind Power Plants", Ed. James \& James (Science Publishers) Ltd., London, UK, 390 p.

Glaucrt, H. 1935, "Windmills and fans. Aerodynamic Theory", ed. F. W. Durand, Vol. 4, Div. L, pp. 324-41. Berlin: Springer. 434 pp.

Hansen, Martin O. L., 2007, "Aerodynamics of wind turbines", Earthscan, 8-12 Cam-den High Street London, NW1 0JH, UK, 2nd ed.

UNITED NATIONS. "Draft outcome document of the United Nations summit forthe adoption of the post-2015 development agenda: Follow-up to the outcome of the millennium summit", New York: UN Headquarters, 2015. Disposableat: https://sustainabledevelopment.un.org/post2015/summit/. Access in: 01/05/2016

URSAIA, G. C. "A regulação da microgeração e minigeração de energia no Brasil”, São Paulo, 2015. Disposableat: <http://www.ambientelegal.com.br/a-regulacao-damicrogeracao-e-minigeracao-de-energia-no-brasil/>. Access in: $02 / 03 / 2016$.

WENZEL, G. M. "Projeto aerodinâmico de pás de turbinas eólicas de eixo horizontal: Trabalho de conclusão de curso", Porto Alegre: PUCRS, 2007. 